\title{
A comparative study of Quality of Life and factors affecting it in children diagnosed with Attention - deficit/ hyperactivity disorder versus Bronchial asthma
}

\author{
Ravindra Kamath ${ }^{1}$, Henal Shah ${ }^{2}$, Sreelakshmi Vaidyanathan ${ }^{3}$ \\ ${ }^{1}$ Professor and Head, \\ ${ }^{2}$ Professor (Additional), \\ ${ }^{3}$ Assistant Professor, \\ Department of Psychiatry, Topiwala National Medical College \& BYL Nair Charitable Hospital, \\ Mumbai. \\ Corresponding author: Sreelakshmi Vaidyanathan \\ Email - sree.vaidyanathan@gmail.com
}

\begin{abstract}
Background and Objectives: Attention deficit hyperactivity disorder (ADHD) is a common childhood disorder which impairs multiple domains of life. The aim is to study and compare the impact of ADHD and Asthma on Quality of Life (QoL) as measured by child and parent ratings and explore the relationship between QoL and socio - demographic factors, illness variables, severity of symptoms and parenting styles. Methods: Study conducted was of cross sectional design at the outpatient services of a tertiary care hospital. 60 children of 8 - 18 years, on treatment (and their parent) were recruited - 30 with ADHD and 30 with Asthma. PedsQL version 4.0 child and parent proxy report was used for QoL, ADHD - RS (ADHD Rating Scale) and GINA (Global Initiative for Asthma) guidelines for severity and Parenting Practices Questionnaire for parenting styles

Results: Parent and child ratings of QoL in both groups were similar. QoL of Asthma group was worse in Physical domain, while psychosocial domains and overall QoL were worse in ADHD group. Increased duration and severity of illness showed reduction in QoL, while treatment showed better QoL in ADHD group only. Parenting style had significant impact on QoL in the ADHD group alone.

Conclusion: ADHD is a childhood disorder with disability comparable to a physical illness like Asthma. QoL of the child can be significantly improved by treatment and focus on parenting styles.
\end{abstract}

Keywords: QoL, ADHD, Asthma, Parenting styles.

(Paper received $-18^{\text {th }}$ August 2018, Peer review completed $-20^{\text {th }}$ January 2019)

(Accepted $-24^{\text {th }}$ January 2019)

\section{INTRODUCTION}

Attention deficit hyperactivity disorder (ADHD) is a neurodevelopmental disorder characterised by developmentally inappropriate inattention, hyperactivity, and impulsivity. ADHD is the most prevalent childhood disorder affecting approximately $3-7 \%$ of school-aged children [1]. Lack of awareness of symptoms of ADHD and the importance of its diagnosis and treatment exists among many, including parents, teachers and healthcare providers [2-3]. Due to this, rather than being provided access to the much needed help and treatment that they require, such children are most often just labelled as "naughty" or "unruly" and punished whereas those with more obvious physical ailments like epilepsy or asthma with visible absenteeism, are more likely to come under the medical radar and seek treatment.

Studies have shown that ADHD leads to impairment in academic, social, emotional domains [4-5] and also essential biological functions like sleep [6]. Looking at Quality of Life (QoL), which is a crucial and holistic health parameter and an important outcome measure [7-8] when compared to individuals without the 
disorder, those with ADHD have an impaired QoL [7, 9-10]. Studies in recent years have brought to light that QoL impairments in patients with ADHD are in fact comparable to other chronic illnesses, like cancer, cerebral palsy [11], diabetes [12] or asthma. [13]. QoL being a multifactorial parameter, various factors like sampling's age group, using different types of QoL scales, choosing proxy or self-report scales (whether filled out by parents or children), and different cultural contexts could affect studies' findings of ADHD and QoL [14]. In our literature review, the main limitation we came across is that most studies so far have used only parent/carer ratings and thus provide a limited understanding of the child's views. Furthermore, we could find no studies in the Indian context. Thus, we decided to study the impact of ADHD on QoL as compared to a physical illness and also look beyond the symptoms of illness into other factors that may influence QoL [15]. This includes parenting style - an important variable in the psychosocial development of a child. Studies show that intolerant or punitive families maintain or exacerbate ADHD symptomatology in vulnerable youngsters [16]. To throw some light on above issues, we conducted a cross sectional study comparing the impact of a chronic psychiatric condition, ADHD and a chronic physical illness, Bronchial Asthma on QoL, as measured by child and parent /carer ratings. We also looked into the relationship between QoL and socio - demographic factors (age, gender, family type, socioeconomic status, parental education), illness variables (duration of illness, duration of treatment, subtype), severity of symptoms and parenting styles among children with ADHD and Asthma.

\section{METHODOLOGY}

Following approval by the Institutional Ethics Committee, 60 children of age group $8-18$ years, on treatment from the outpatient services of a tertiary care hospital in Mumbai, Maharashtra, were recruited as a convenience sample. 30 were children with recently established diagnosis of ADHD (as per DSM IV TR criteria for ADHD and treatment of less than 3 months) - from the Child Psychiatry services and 30 were children with established diagnosis of Bronchial Asthma (as per GINA guidelines) - from the Pediatric services. Only those cases where parent/ carer and child were willing to give consent / assent were included. Children with low intelligence (ascertained clinically on interview), with other psychiatric/ medical co morbidities and with an acute exacerbation of asthma at time of interview were excluded from the study.

Parent/ carer and child completed the standardized questionnaires independently -

1. Details of demographic data and illness variables were collected.

2. Pediatric Quality of Life Scale (PedsQL): generic core scale, both child self - report (age appropriate version for children, i.e. 8 - 12 years and teens, i.e. $13-18$ years) and parallel parent proxy - report was used for QoL. It is a 23 item 5 - point Likert scale with good reliability ( 0.88 for child self - report and 0.90 for parent proxy report) and validity, and comprising of 4 domains: Physical (About health and activities; "It is hard for me to run"), Emotional (About feelings; "I feel sad or blue"), Social Functioning (About getting along with others; "Other kids tease me") and School functioning (About school; "It is hard to pay attention in class") and a total score. A higher PedsQL score indicates a better QoL [17].

3. ADHD Severity Rating Scale: Data on symptom severity for the ADHD group was collected using the ADHD Rating Scale - IV (ADHD - RS - IV), completed by the clinician following interview with the parent / carer (Cronbach alpha is 0.795 for the total score, 0.724 for the Inattention subscale and 0.825 for the Hyperactive / Impulsive subscale; Item to total correlation ranges from 0.25 to 0.51) [18] and for the Asthma group using GINA guidelines [19].

4. Parenting Practices Questionnaire: was used to measure characteristics of authoritative, authoritarian and permissive parenting styles [20].

\section{STATISTICAL ANALYSIS}

Data obtained was statistically analyzed using SPSS version 20.0. Independent $t$ test was used to compare QoL between the two groups and factors affecting QoL (socio demographic factors, illness variables, severity, parenting styles) were analyzed using correlation coefficients, ANOVA and Simple linear regression. $p$ value of $<0.05$ was considered statistically significant. 


\section{RESULTS}

Socio demographic profile of both groups was found to be similar with mean age being 11 years, $67 \%$ of children being male, $63 \%$ of families were nuclear families, $45 \%$ of parents were educated up to X Std. and $50 \%$ families belonged to Class II Socio - economic class of Modified B.G. Prasad's classification. In the ADHD group, mean duration of illness was 4.66 years and mean duration of treatment received was 1.85 months, while it was 1.58 years and 11.13 months in the Asthma group respectively. In the ADHD group $(n=30), 5$ were of inattentive subtype, 5 of hyperactive / impulsive subtype and 20 of mixed subtype. In the Asthma group ( $\mathrm{n}=30$ ), 6 were of Mild intermittent subtype, 15 of Mild persistent subtype, 9 of Moderate persistent subtype and none of Severe persistent subtype. The symptom severity on the ADHD - RS scale showed mean scores as follows: Inattention subscale $=17.97$, Impulsivity $/$ Hyperactivity subscale $=18.17$ and Total $=36.13$.

Comparison of child and parent ratings of QoL: showed lower scores in the parent report of both the groups, but this difference was not statistically significant. In both the groups, the lowest mean scores were in the domain of school functioning.

Table 1: Comparison of QoL scores (parent report) of ADHD and Asthma groups

\begin{tabular}{|c|c|c|c|c|c|}
\hline \multirow[t]{2}{*}{ QoL Domains } & & \multirow[t]{2}{*}{ Mean } & \multirow[t]{2}{*}{ S.D. } & \multicolumn{2}{|c|}{$\mathrm{t}-$ test } \\
\hline & & & & $\mathrm{t}$ & Sig.(2-tailed) \\
\hline \multirow[t]{2}{*}{ Physical } & ADHD & 98.97 & 1.49 & \multirow[t]{2}{*}{12.190} & \multirow[t]{2}{*}{$.000 * *$} \\
\hline & Asthma & 71.78 & 12.12 & & \\
\hline \multirow[t]{2}{*}{ Emotional } & ADHD & 80.00 & 8.51 & \multirow[t]{2}{*}{6.021} & \multirow[t]{2}{*}{$.000 * *$} \\
\hline & Asthma & 93.33 & 8.64 & & \\
\hline \multirow[t]{2}{*}{ Social } & ADHD & 74.00 & 14.29 & \multirow[t]{2}{*}{5.713} & \multirow[t]{2}{*}{$.000 * *$} \\
\hline & Asthma & 91.17 & 8.17 & & \\
\hline \multirow[t]{2}{*}{ School functioning } & ADHD & 68.33 & 11.55 & \multirow[t]{2}{*}{1.086} & \multirow[t]{2}{*}{.282} \\
\hline & Asthma & 71.83 & 13.36 & & \\
\hline \multirow{2}{*}{$\begin{array}{l}\text { Psychosocial health } \\
\text { summary }\end{array}$} & ADHD & 74.11 & 7.98 & \multirow[t]{2}{*}{4.972} & \multirow[t]{2}{*}{$.000 * *$} \\
\hline & Asthma & 85.44 & 9.60 & & \\
\hline \multirow[t]{2}{*}{ Total } & ADHD & 80.33 & 6.04 & \multirow[t]{2}{*}{0.804} & \multirow[t]{2}{*}{.425} \\
\hline & Asthma & 82.03 & 9.90 & & \\
\hline
\end{tabular}

Table 2: Comparison of QoL scores (child report) in the ADHD and Asthma groups

\begin{tabular}{|c|c|c|c|c|c|}
\hline \multirow[t]{2}{*}{ QoL Domains } & & \multirow[t]{2}{*}{ Mean } & \multirow[t]{2}{*}{ S.D. } & \multicolumn{2}{|c|}{$\mathrm{t}-$ test } \\
\hline & & & & $\mathrm{t}$ & Sig.(2-tailed) \\
\hline \multirow[t]{2}{*}{ Physical } & ADHD & 99.17 & 1.39 & \multirow[t]{2}{*}{11.199} & \multirow[t]{2}{*}{$.000 * *$} \\
\hline & Asthma & 73.97 & 12.25 & & \\
\hline \multirow[t]{2}{*}{ Emotional } & ADHD & 82.50 & 8.69 & \multirow[t]{2}{*}{5.723} & \multirow[t]{2}{*}{$.000 * *$} \\
\hline & Asthma & 95.17 & 8.46 & & \\
\hline \multirow[t]{2}{*}{ Social } & ADHD & 76.33 & 14.50 & \multirow[t]{2}{*}{5.496} & \multirow[t]{2}{*}{$.000 * *$} \\
\hline & Asthma & 92.67 & 7.40 & & \\
\hline \multirow[t]{2}{*}{ School functioning } & ADHD & 70.17 & 12.07 & \multirow[t]{2}{*}{0.982} & \multirow[t]{2}{*}{.330} \\
\hline & Asthma & 73.50 & 14.15 & & \\
\hline \multirow{2}{*}{$\begin{array}{c}\text { Psychosocial health } \\
\text { summary }\end{array}$} & ADHD & 76.33 & 8.75 & \multirow[t]{2}{*}{4.545} & \multirow[t]{2}{*}{$.000 * *$} \\
\hline & Asthma & 87.11 & 9.60 & & \\
\hline \multirow[t]{2}{*}{ Total } & ADHD & 82.04 & 6.67 & \multirow[t]{2}{*}{0.816} & \multirow[t]{2}{*}{.418} \\
\hline & Asthma & 83.83 & 9.94 & & \\
\hline
\end{tabular}


Between group comparisons: (a). QoL: (Table 1 \& 2) Significant difference found in the Physical domain $(p=0.000)$, with lower scores in the Asthma group and in the Emotional, Social and Psychosocial domains $(p=0.000)$, with lower scores in the ADHD group in both parent and child ratings. (b). Parenting styles: Showed no significant correlations.

Correlations with QoL: As it has been established that there is no significant difference between the parent and child ratings of QoL, for the correlations only the child report of QoL has been used.

(a). Socio - demographic factors (age, gender, family type, socioeconomic status, parental education): No significant correlations were found in both groups.

(b). Illness duration (years): (Table 3) In both groups, illness duration was significantly negatively correlated with the QoL domains (Emotional, School functioning, Psychosocial Health Summary and Total QoL), i.e., increased symptom severity was associated with poorer $\mathrm{QoL}$ in the above mentioned domains $(\mathrm{p}<0.05$ in ADHD group, $p=0.01$ in Asthma group). No significant correlation was observed with the Physical domain of QoL.

Table 3: Correlation of illness and treatment duration of both groups with QoL domains

\begin{tabular}{|c|c|c|c|c|c|c|c|c|}
\hline & \multirow{2}{*}{$\begin{array}{l}\text { Subject } \\
\text { group }\end{array}$} & & \multicolumn{6}{|c|}{ QoL domains } \\
\hline & & & Physical & Emotional & Social & $\begin{array}{c}\text { School } \\
\text { functioning }\end{array}$ & $\begin{array}{c}\text { Psychosocial } \\
\text { health } \\
\text { summary }\end{array}$ & Total \\
\hline \multirow{4}{*}{$\begin{array}{l}\text { Duration } \\
\text { of illness } \\
\text { (years) }\end{array}$} & \multirow[t]{2}{*}{ ADHD } & $r$ & .028 & -.480 & -.264 & -.410 & -.526 & -.520 \\
\hline & & $\mathrm{p}$ & .882 & $.007 * *$ & .158 & $.025^{*}$ & $.003^{* *}$ & $.003^{* *}$ \\
\hline & \multirow[t]{2}{*}{ Asthma } & $r$ & -.272 & -.496 & -.458 & -.469 & -.496 & -.444 \\
\hline & & $\mathrm{p}$ & .146 & $.005^{* *}$ & $.011^{*}$ & $.009 * *$ & $.005^{\star * *}$ & $.014^{*}$ \\
\hline \multirow{4}{*}{$\begin{array}{l}\text { Duration } \\
\text { of } \\
\text { treatment } \\
\text { (months) }\end{array}$} & \multirow[t]{2}{*}{$\mathrm{ADHD}$} & $\mathrm{r}$ & -.098 & -.014 & .701 & .306 & .561 & .551 \\
\hline & & $\mathrm{p}$ & .606 & .942 & $.000 * *$ & .101 & $.001^{* *}$ & $.002^{* *}$ \\
\hline & \multirow[t]{2}{*}{ Asthma } & $r$ & -.121 & -.204 & -.274 & -.253 & -.257 & -.224 \\
\hline & & $\mathrm{p}$ & .524 & .279 & .143 & .177 & .171 & .235 \\
\hline
\end{tabular}

* - Correlation is significant at 0.05 level (2-tailed); ** - Correlation is significant at 0.01 level (2-tailed)

(c) Duration of treatment (months): (Table 3) In the ADHD group duration of treatment was significantly positively correlated with the QoL domains (Social, Psychosocial Health Summary and Total QoL), ( $\mathrm{p}<$ $0.01)$ i.e., increased treatment duration was associated with improvement in QoL in the above-mentioned domains. No significant correlation was found in the Asthma group.

(d) Subtypes: An analysis of variance showed that the subtypes have a significant effect on QoL. In the ADHD group (Table 4), this was seen in the Social $(F=4.649 ; \mathrm{p}=0.018)$ and School functioning $(\mathrm{F}=$ $4.135 ; p=0.027$ ) domains with post hoc analysis (Scheffe) showing Inattentive subtype to have significantly higher QoL than the other two subtypes. In the Asthma group (Table 5), there was significant differences in all the domains of QoL $(p=0.000)$ with post hoc analysis showing highest QoL in Intermittent subtype, followed by Mild persistent and least QoL in Moderate persistent subtype.

(e) Symptom severity: In ADHD group (Table 6), it was significantly negatively correlated with the QoL domains (Emotional, Social, School functioning, Psychosocial Health Summary and Total QoL), i.e., increased symptom severity was associated with reduction in the above mentioned domains of QoL of the child but no significant correlation was found with the Physical domain. Table 6 further shows that the severity of ADHD significantly predicts the QoL $(F=55.66, p=0.00$, R Square $=0.66)$, i.e. for every one unit increase in ADHD severity there will be a .816 unit decrease in QoL (Beta $=-0.816, t=7.46, p=0.000$ ). In the Asthma group, as seen in Table 5, higher severity has lower QoL. 
Table 4: Association of subtypes of ADHD with QoL and its domains

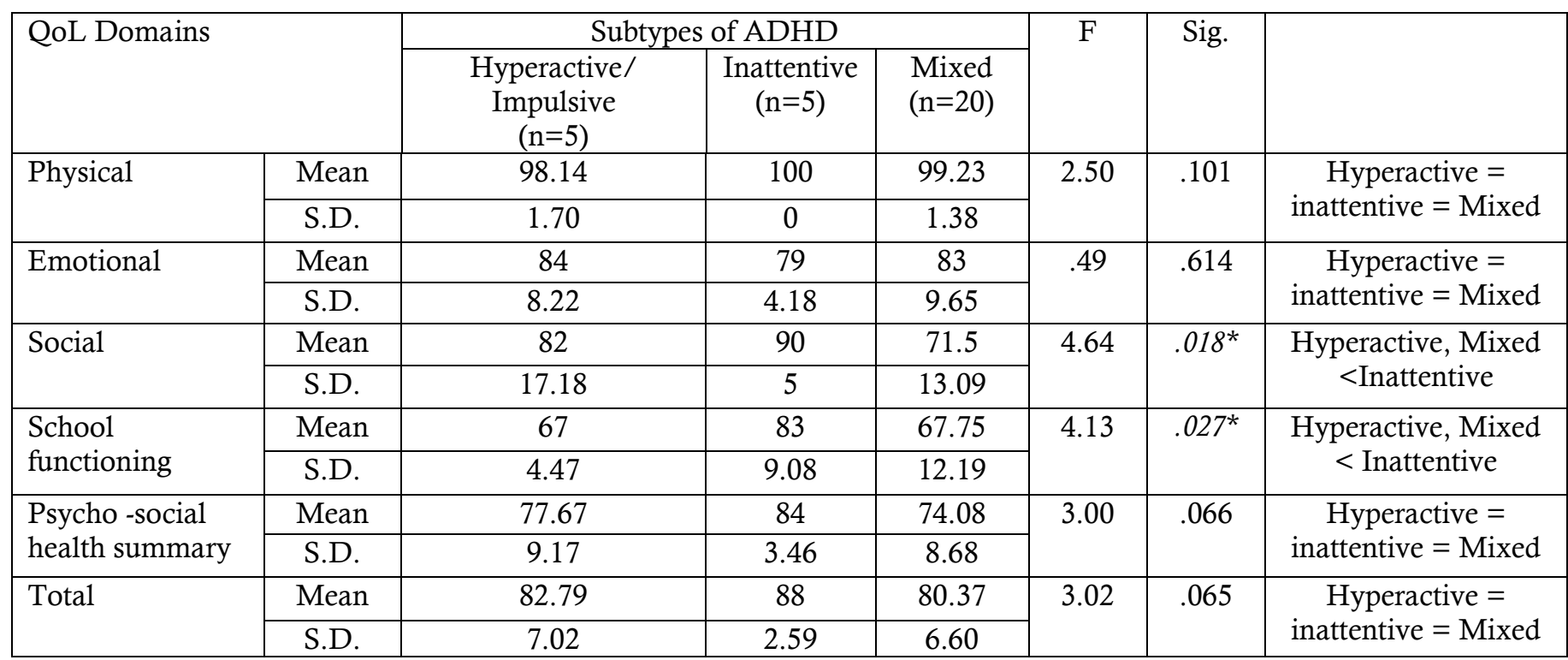

* - Correlation is significant at 0.05 level (2-tailed), ${ }^{* *}$ - Correlation is significant at .01 level (2-tailed)

Table 5: Association of the subtypes of Asthma with QoL and its domains

\begin{tabular}{|c|c|c|c|c|c|c|c|}
\hline \multirow{2}{*}{\multicolumn{2}{|c|}{ QoL Domains }} & \multicolumn{3}{|c|}{ Subtypes of Asthma } & \multirow[b]{2}{*}{$\mathrm{F}$} & \multirow{2}{*}{ Sig. } & \\
\hline & & \multirow{2}{*}{$\begin{array}{c}\text { Mild } \\
\text { Intermittent } \\
(\mathrm{n}=6)\end{array}$} & \multirow{2}{*}{$\begin{array}{c}\begin{array}{c}\text { Mild } \\
\text { Persistent } \\
(\mathrm{n}=15)\end{array} \\
75.03\end{array}$} & $\begin{array}{c}\text { Moderate } \\
\text { Persistent } \\
(\mathrm{n}=9)\end{array}$ & & & \\
\hline Physical & Mean & & & 61.12 & \multirow{2}{*}{35.96} & \multirow{2}{*}{$.000^{*}$} & \multirow{2}{*}{$\begin{array}{l}\text { Mod < Mild } \\
<\text { Intermittent }\end{array}$} \\
\hline & S.D. & 0 & 9.12 & 1.63 & & & \\
\hline \multirow[t]{2}{*}{ Emotional } & Mean & 100 & 100 & 83.89 & \multirow[t]{2}{*}{50.30} & \multirow{2}{*}{$\begin{array}{c}.000^{*} \\
*\end{array}$} & \multirow{2}{*}{$\begin{array}{c}\text { Mod }< \\
\text { Mild, Intermittent }\end{array}$} \\
\hline & S.D. & 0 & 0 & 7.41 & & & \\
\hline \multirow[t]{2}{*}{ Social } & Mean & 100 & 95.67 & 82.78 & \multirow[t]{2}{*}{72.56} & \multirow{2}{*}{$.000^{*}$} & \multirow{2}{*}{$\begin{array}{l}\text { Mod < Mild } \\
<\text { Intermittent }\end{array}$} \\
\hline & S.D. & 0 & 3.72 & 2.64 & & & \\
\hline \multirow{2}{*}{$\begin{array}{l}\text { School } \\
\text { functioning }\end{array}$} & Mean & 93.33 & 76.33 & 55.56 & \multirow[t]{2}{*}{169.30} & \multirow{2}{*}{$\begin{array}{c}.000^{*} \\
*\end{array}$} & \multirow{2}{*}{$\begin{array}{l}\text { Mod < Mild } \\
<\text { Intermittent }\end{array}$} \\
\hline & S.D. & 2.58 & 3.52 & 5.27 & & & \\
\hline \multirow{2}{*}{$\begin{array}{l}\text { Psycho -social } \\
\text { health summary }\end{array}$} & Mean & 97.78 & 90.67 & 74.07 & \multirow[t]{2}{*}{120.20} & \multirow{2}{*}{$.000^{*}$} & \multirow{2}{*}{$\begin{array}{l}\text { Mod < Mild } \\
<\text { Intermittent }\end{array}$} \\
\hline & S.D. & 0.86 & 2.07 & 5.08 & & & \\
\hline \multirow[t]{2}{*}{ Total } & Mean & 95.98 & 86.76 & 70.84 & \multirow[t]{2}{*}{102.73} & \multirow[t]{2}{*}{$.000^{* *}$} & \multirow{2}{*}{$\begin{array}{l}\text { Mod < Mild } \\
<\text { Intermittent }\end{array}$} \\
\hline & S.D. & 0.65 & 3.67 & 4.22 & & & \\
\hline
\end{tabular}

* - Correlation is significant at 0.05 level (2-tailed), ** - Correlation is significant at .01 level (2-tailed)

Table 6: Correlation of ADHD symptom severity and QoL domains

\begin{tabular}{|c|c|c|c|c|c|c|c|}
\hline \multirow{4}{*}{ Severity } & & \multicolumn{6}{|c|}{ QoL domains } \\
\hline & & Physical & Emotional & Social & $\begin{array}{c}\text { School } \\
\text { functioning }\end{array}$ & $\begin{array}{c}\text { Psychosocial } \\
\text { health summary }\end{array}$ & Total \\
\hline & Pearson's correlation & -.111 & -.444 & -.717 & -.608 & -.823 & -.816 \\
\hline & \begin{tabular}{|l} 
Sig. (2-tailed) \\
Siled
\end{tabular} & .558 & $.014^{*}$ & $.000^{* *}$ & $.000^{* *}$ & $.000^{* *}$ & $.000^{* *}$ \\
\hline \multicolumn{8}{|c|}{${ }^{*}$ - Correlation is significant at 0.05 level (2-tailed); ${ }^{* *}$ - Correlation is significant at 0.01 level (2-tailed) } \\
\hline \multicolumn{8}{|c|}{ Linear regression of ADHD severity with Total QoL } \\
\hline \multirow{3}{*}{\multicolumn{2}{|c|}{ ADHD severity }} & \multirow{2}{*}{\multicolumn{4}{|c|}{ Standard coefficient }} & \multirow[b]{3}{*}{746} & \multirow[t]{2}{*}{ Sig. } \\
\hline & & & & & & & \\
\hline & & \multicolumn{4}{|c|}{$\frac{\text { Beta }}{-.816}$} & & $.000^{* \star}$ \\
\hline
\end{tabular}


(f) Parenting style: In the ADHD group (Table 7), Authoritarian style of parenting was significantly negatively correlated with QoL $(p=0.01)$ while Authoritative style of parenting was significantly positively correlated with QoL $(p=0.002)$. These parenting styles significantly predict the QoL - for every one unit increase in Authoritarian parenting style there will be a .465 unit decrease in $\mathrm{QoL}$ ( $\mathrm{F}=7.728, \mathrm{p}=0.01, \mathrm{R}$ Square $=.21$, Beta $=-.465, \mathrm{t}=2.78, \mathrm{p}=0.01$ ) while for every one unit increase in Authoritative parenting style there will be a .534 unit increase in $\mathrm{QoL}(\mathrm{F}=11.16, \mathrm{p}=0.002$, $\mathrm{R}$ Square $=.28$, Beta $=.534, \mathrm{t}=3.34$, $p=0.002)$. No significant correlations were seen in the Asthma group.

Table7: Correlation of Parenting style and QoL - ADHD Group

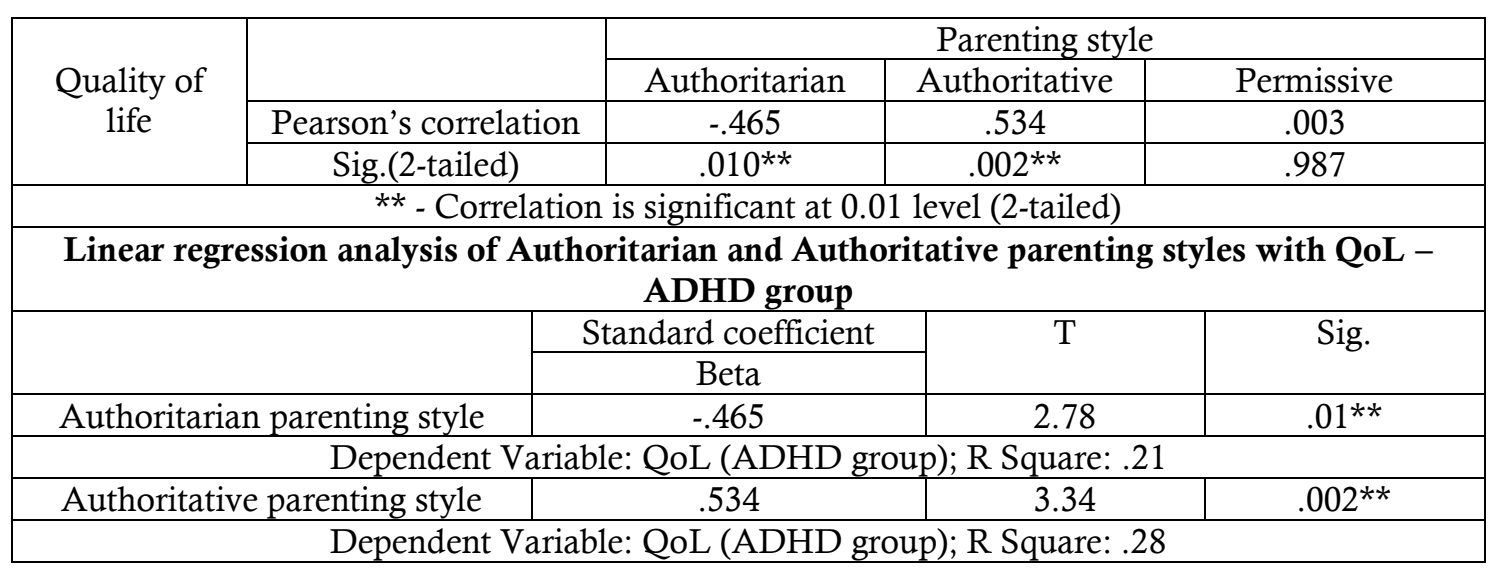

\section{DISCUSSION}

This study provides child and parent rated data on QoL of children diagnosed with ADHD and Asthma and factors affecting them. In our study, parent and child ratings did not differ. Some studies have shown no significant differences between parent and child ratings of QoL, [11, 21-22] though a recent review by Galloway and Newman found that children with ADHD rated their QoL higher than their parents [23] which could be the result of factors like positive illusory bias, [24] the attention difficulties of the child coming in the way of answering [25] or increased parenting stress experienced by parents of children with ADHD. $[7,26]$ Our sample size could have been a limitation in this case.

On comparing the QoL scores of the two groups, overall QoL is impaired in both groups of children. However, in the physical function domain, child and parent rating of QoL in Asthma group was worse than the ADHD group while it was vice versa in the psychosocial domains. Current published evidence also suggests that ADHD has a comparable overall impact on QoL in comparison to chronic physical illnesses, with a greater impact on psychosocial rather than physical domains $[7,14]$.

QoL (Overall and Psychosocial domains) was found to deteriorate with increasing duration of illness in both the groups, but a point of interest is that increasing duration of treatment showed improved QoL scores in ADHD, but not in Asthma. This is probably due to children having repeated exacerbations of asthma despite being on medications, due to various environmental triggers. This further highlights the essentiality of adequate treatment of ADHD and the resultant transformation it can bring in the life of the child. Subtype of ADHD was found to have an impact on the QoL with the Inattentive subtype having a better QoL, especially in the Social and School functioning domains which is in accordance with literature [27]. The Inattentive subtype has comparatively fewer behavioral issues and usually comes to light only in higher classes due to poor academic performance. In both the groups in the study, we found that increase in severity of illness was associated with poorer QoL which is in accordance with many previous studies [27-30].

We found no significant differences in parenting styles between the groups, but Parenting style was seen to significantly impact QoL in the ADHD group only. This suggests an important influence of parenting style in ADHD as previously hypothesized in the diathesis - stress model of ADHD [16] and in studies showing an improvement in ADHD symptoms with parents having been taught alternative parenting skills [31] and 
could be due to the negative aspects of the child's behaviour influencing the parent's response or vice versa. [32].

\section{CONCLUSION}

ADHD is a childhood disorder that is as disabling as a chronic physical illness like Asthma and QoL of the child can be significantly improved by treatment and focus on parenting styles, both of which are factors that clinicians can work on through measures like psycho education and parenting skills training and thus improve overall outcomes and quality of care. The limitations of this study are that it is cross sectional and hospital based. We believe that further prospective studies, especially with interventions on parenting skills are necessary to obtain a consensus opinion of factors that can improve QoL in addition to treatment.

\section{REFERENCES}

1. American Psychiatric Association. Diagnostic and statistical manual of mental disorders. $4^{\text {th }}$ ed.; 1994

2. Hamed AM, Kauer AJ, Stevens HE. Why the Diagnosis of Attention Deficit Hyperactivity Disorder Matters. Front Psychiatry 2015;6:168

3. Mukherjee S, Shah HR, Ramanathan, S, Dewan, M. Knowledge and attitudes about Attention deficit/hyperactivity disorder and Specific learning disorder in an urban Indian population. J Nerv Ment Dis 2016;204(6):458-63.

4. Spencer J. Thomas, MD, Biederman JMD, Mick E. Attention-Deficit/Hyperactivity Disorder: Diagnosis, Lifespan, Co morbidities, and Neurobiology. J Pediatr Psychol 2007;32(6):631-42.

5. Shah H, Rupani K, Mukherjee S, Kamath R. A comparative study of family impact in children with attention deficit hyperactivity disorder (ADHD) and learning disability. Indian Journal of Mental Health 2016;3(1):70-8.

6. Vaidyanathan S, Shah H, Gayal T. J Can Acad Child Adoelsc Psychiatry 2016;25(3):145-51.

7. Danckaerts M, Sonuga - Barke EJS, Banaschewski T, et al. The quality of life of children with attention deficit/hyperactivity disorder: a systematic review. Eur Child Adolesc Psychiatry 2010;19:83-105.

8. Saxena S, et al. Quality of life assessment: The World Health Organization perspective. Eur Psychiatry 1997;12:263-6.

9. Coghill D, Danckaerts M, Sonuga-Barke E, Sergeant J. Practitioner review: quality of life in child mental healthconceptual challenges and practical choices. J Child Psychol Psychiatry 2009;50:544-61.

10. Velo S, Kereszteny A, Szentivanyi D, Balazs J. Quality of life of patients with attention-deficit/hyperactivity disorder: systematic review of the past 5 years. Neuropsychopharmacol Hung 2013;15:73-82.

11. Varni JW, Burwinkle TM. The PedsQL as a patient-reported outcome in children and adolescents with attentiondeficit/hyperactivity disorder: a population-based study. Health Qual Life Outcomes 2006;4:26.

12. Coghill D, Hodgkins P. Health-related quality of life of children with attention-deficit/hyperactivity disorder versus children with diabetes and healthy controls. Eur Child Adolesc Psychiatry 2016;25:261-71.

13. Escobar R, Soutullo CA, Hervas A, Gastaminza X, Polavieja P, Gilaberte I. Worse quality of life for children with newly diagnosed attention-deficit/hyperactivity disorder, compared with asthmatic and healthy children. Pediatrics 2005;116(3):364-9.

14. Ozden SU, Gulser SD, Zeynep G. The Quality of Life (QoL) in Attention Deficit Hyperactivity Disorder (ADHD). In: Dr. Jill MN, Ed. ADHD - New Directions in Diagnosis and Treatment. In Tech; 2015. pp. 197-230

15. Mulraney M, Giallo R, Sciberras E, Lycett K, Mensah F, Coghill D. ADHD Symptoms and Quality of Life Across a 12-Month Period in Children With ADHD: A Longitudinal Study. J Attent Disord 2017;

16. Carr A. The Handbook of Child and Adolescent Clinical Psychology. A Contextual Approach. London: Routledge; 1999.

17. Varni J, Seid M, Kurtin P. PedsQL 4.0: Reliability and validity of the Pediatric Quality of Life Inventory version 4.0 generic core scales in healthy and patient populations. Med Care 2001;39:800-12.

18. Zhang S, Faries DE, Vowles M, Michelson D. ADHD Rating scale IV: psychometric properties from a multinational study as a clinician-administered instrument. Int J Methods Psychiatr Res 2005;4(4):186-201.

19. Global Initiative for Asthma (GINA) Executive Committee. Global strategy for asthma management and prevention, In: Global Initiative for Asthma (GINA); 2010.

20. Robinson CC, Mandleco B, Olsen SF, Hart CH. Authoritative, authoritarian, and permissive parenting practices: Development of a new measure. Psychol Rep 1995;77(3):819-30. 
21. Marques JCB, Oliveira JA, Goulardins JB, Nascimento RO, Lima AMV, Casella EB. Comparison of child selfreports and parent proxy-reports on quality of life of children with attention deficit hyperactivity disorder. Health Qual Life Outcomes 2013;11(1):186.

22. Limbers CA, Ripperger-Suhler J, Heffer RW, Varni JW. Patient-reported Pediatric Quality of Life InventoryTM 4.0 generic core scales in pediatric patients with attention-deficit/hyperactivity disorder and comorbid psychiatric disorders: feasibility, reliability, and validity. Value Health 2011;14(4):521-30.

23. Galloway $\mathrm{H}, \mathrm{Newman} \mathrm{E}$. Is there a difference between child self-ratings and parent proxy-ratings of the quality of life of children with a diagnosis of attention-deficit hyperactivity disorder (ADHD)? A systematic review of the literature. Attention Deficit and Hyperactivity Disorders 2017;9(1):11-29.

24. Hoza B, Pelham WE Jr, Dobbs J, Owens JS, Pillow DR. Do boys with attention deficit/hyperactivity disorder have positive illusory self-concepts? J Abnorm Psychol 2002;111:268-78.

25. Owens JS, Hoza B. The role of inattention and hyperactivity/ impulsivity in the positive illusory bias. J Consult Clin Psychol 2003;71:680-91.

26. Theule J, Wiener J, Tannock R, Jenkins JM. Parenting stress in families of children with ADHD: a meta-analysis. J Emot Behav Disord 2010;21(1):3-17.

27. Landgraf JM, Rich M, Rapaport L. Measuring quality of life in children with Attention Deficit Hyperactivity Disorder and their family. Arch Ped Adolesc Med 2002;156:384-91.

28. Merikallio VJ, Mustalahti K, Remes ST, Valovirta EJ, Kaila M. Comparison of quality of life between asthmatic and healthy school children. Pediatr Allergy Immunol 2005;16(4):332-40.

29. Mohangoo AD, De Koning HJ, Mangunkusumo RT, Raat H. Health-Related Quality of Life in Adolescents with Wheezing Attacks. J Adolesc Health 2007;41(5):464-71.

30. Klassen AF, Miller A, Fine S. Health-related quality of life in children and adolescents who have a diagnosis of attention-deficit/hyperactivity disorder. Pediatrics 2004;114(5):541-7.

31. Bor W, Sanders MR, Markie DC. The effect of the Triple-P Positive Parenting Programme on pre-school children with co-occurring disruptive behaviours and attention/hyperactive difficulties. J Abnorm Child Psychol 2002;30: 571-87.

32. Gardner FEM. The quality of joint activity between mothers and their children with behavior problems. J Child Psychol Psychiatry 1994;35:935-48.

$* * * * * * * * * * * * * * * * * * * * * * * * * * * * * * * * * * * *$

Acknowledgements - Nil

Conflict of Interest - Nil

Funding - Nil 